\title{
Statistical Evaluation of RCM's Performances in simulation of Climate variables at Upper Awash Basin, Case study of Akaki Catchment
}

Bekan Chelkeba Tumsa ( $\sim$ bekanchelkeba@gmail.com )

Jimma University Institute of Technology https://orcid.org/0000-0001-6173-0961

\section{Research Article}

Keywords: Annual cycle, Climate Models, Inter-annual variability, Performance, RCMs

Posted Date: October 25th, 2021

DOI: https://doi.org/10.21203/rs.3.rs-1012630/v1

License: (c) (1) This work is licensed under a Creative Commons Attribution 4.0 International License.

Read Full License 


\section{Abstract}

The main focus of this study was to investigate and evaluate the Performance of Four Regional Climate Models irrespective of their capability in simulating mean precipitation and Temperature. In this fact and concern, the evaluation of those climate models was basically on how they simulate mean annual climatology, annual cycle and interannual variability of precipitation, maximum and minimum temperature over the entire catchment. All observed data used for the baseline period of 1980-2006 was obtained from Ethiopian National Meteorological Agency and RCM data was extracted from CORDEXAfrica-44 using grid points. RCM shows significant bias and almost all of them simulate those climate variables' at different levels. In the analysis of the annual cycle of precipitation during the summer season, all RCM was underestimated. However, RACM022T and RCA4 show better adjustment at the simulation of both precipitation and Temperatures despite their significant bias. The bias was deliberately associated with the higher error in simulating maximum and minimum temperature at the highest topography found at sebeta and Addis Ababa catchments. The inter-annual variability of precipitations and temperature was shown as great evidence where the region is under the impact of climate change specifically when the trend of annual projected temperature shown incremental modality. As far as concern the mean climatology analysis by statistical parameters, almost all models perform nearly equal excluding the seasonal point of view in which RCMs performed quite differently during season analysis. In all aspects and evidence by statistically evaluated output realize that RACMO22T and RCA4 were better performed at upper awash catchments although some of their bias and uncertainty were available. Generally, the performance of Regional climate models was different at different catchments along with the specified locations and topographies. Furthermore, the seasonal analysis over Akaki catchment indicates that climate models were more capable of simulating wet season than dry.

\section{Introduction}

Climate models are very important in predicting and forecasting current and future climate impacts on global water resources due to their extensive simulation of precipitation and temperatures (Matiu et al., 2020). Besides this, Global climate models are capable and suitable in predicting climate change on water resources even if a certain limitation is available with it (Endris, Philip Omondi, et al., 2013). Indeed, dynamically downscaled Regional climate models are a credible and more alternative solution than GCM in identifying and evaluating climate impact generated from rainfall and surface temperature on streamflow and surface runoff during in use of hydrological models (Crop et al., 2012). Ethiopia is more vulnerable to climate change because of the less flexibility to adjust the economic structure and is largely dependent on agriculture in which climate change has far-reaching implications in the region (Menna, 2017).

According to the (Climate Change 2014 Synthesis Report IPCC, 2014) findings, developing countries, such as Ethiopia, will be more vulnerable to climate change due to its large part is arid and semiarid, and is highly prone to drought and desertification. Accordingly, the A-wash basin is the most irrigable area in Ethiopia by which many farmers take this basin as the guarantee of their food security (Asore, 2012). 
However, recently climate change is one of the causes for the depletion of agricultural products in this region that impact many farmers and their economic productivity to be insufficient as usual (Taye, 2018). Therefore, assessing the vulnerability of climate change impact, mapping, and preparing adaptation options as part of the national program is very crucial for the country (Gashaw and Didita, 2015). For all these reason and facts, the impact of climate change on water resources are the most crucial research agenda currently in worldwide level. To pave the way for further study and realization of the impact of climate change on water resources, it is very important to incorporate climate models by considering their performance in simulating Precipitation and Temperatures (Worku et al., 2018). This assessment of the climate model's performance will encourage a researcher to prioritize which climate model is more relevant in simulating climate variables during climate change impact assessment subjectively (Tan et al., 2020). The hydrologic effect of each set of meteorological data of inputs was determined by comparing the resultant simulations to those created by using the same hydrologic model in different various ways to recognize and estimate its diverse impacts (Mekonnen et al., 2011). According to climate model predictions, using several scenarios of greenhouse gas emissions, the global mean temperature has been increasing from $1.1^{\circ} \mathrm{C}$ to $6.4^{\circ} \mathrm{C}$ in the next 100 years and it is differently simulated by different climate models (IPCC, 2014). On the other hand, the shift in precipitation and temperature patterns affects the hydrological process and cycles to the availability of water resources in particular which is predicted and simulated by climate models along with observed. Therefore, the importance of general circulation models (GCMs) is widely known for providing climate forecasts and to cope with unfavorable climate variability (Fang et al., 2015). The magnitude and direction of climate change impact depend on the catchment, hydrological model, climate models (GCM /RCM) and climate change scenarios used, and the flow index examined (Zhang et al., 2016). On the other side, the developments of new RCM leads to the other opportunity for the scientists to analyze the effects of climate change as it inclusively considered higher spatial resolution and further reliable outcomes on a regional scale than General Circulation Models (GCMs) (Kang et al., 2020).

Furthermore, climate models developed and available right now also has a different performance of simulating precipitation, temperatures, and other climate variables. In other words, climate models that have been developed with the specified resolution are not consistently predict and simulate the climate variables that are intended to cause climate change (Dibaba, Miegel, and Demissie, 2019). Moreover, this impact of climate change on hydrological variables and its processes has been studied extensively, particularly on surface runoff, groundwater flow, and streamflow by analyzing projected and downscaled climatic data and by using different CORDEX regional climate models and hydrological models (Yesuf et al., 2016). This is particularly prominent in semi-arid and arid Climate regions because in these regions, water resources, primarily streamflow and surface runoff, are highly sensitive to climate change; a small change in climate variables may result in significant variations of hydrological cycles and subsequence changes of regional water resources (Gunathilake et al., 2020). This study mainly focuses on the Statistical Evaluation of Four Regional Climate Models Performance to prioritize them in simulating climate variables Specifically Precipitations and Surface temperatures. 


\section{Materials And Methods}

\section{Description of the study area}

Akaki River Sub-basin is located in the Upper Awash basin and serves many populations along the center of this watershed as a source for irrigating diverse land and generation of hydropower. This river is a tributary of Awash River and also has a great contribution directly to Abba Samuel Reservoir which is generating hydropower for national use. This catchment is geographically bounded between $8^{\circ} 46^{\prime}$ to $9^{\circ} 14^{\prime} \mathrm{N}$, latitude, and $38^{\circ} 34^{\prime}$ to $39^{\circ} 04^{\prime} \mathrm{E}$, longitudinal covering an area of about $9526 \mathrm{~km}^{2}$ with $97.6 \mathrm{~km}$ boundary length as shown on (Figure 1).

\section{Climate}

Akaki River watershed has a subtropical highland climate and geographically found near to the equator and as a result, its temperature is remarkably constant from month to month. Based on the recorded monthly averages for the 25 years, period (1980-2005), the mean monthly minimum and maximum temperatures vary from $7^{\circ} \mathrm{C}$ to $11^{\circ} \mathrm{C}$ and $21^{\circ} \mathrm{C}$ to $28^{\circ} \mathrm{C}$, respectively. The lowest temperature of the study area was $7^{\circ} \mathrm{C}$, which was registered in November and December, and the maximum temperature was $28^{\circ} \mathrm{C}$ registered in March and May. The main rainy season for Akaki watershed was late June to early September, also characterized by dry winter, which was the dry season, i.e., in December, January, February and little bit in the mid of march of the area. Generally, the project area has an average annual rainfall of $1965 \mathrm{~mm} /$ year.

\section{Observed Data}

Observed data was required for two main purposes in this study. The first one is that observed data was used as reference to compare with the simulated data from four RCM models in order to recognize the available deviations that encouraged for estimating their performances. The second one, it is used to project the simulated climate variables by different Regional climate models and verify the depth of the variation among them relative to the reference data's and label according to their performances. These observed data was Recorded and collected from the specified location of four station found in the entire catchment. These stations were contain missing data for both precipitation and temperature data and filled with XIstat2016 before further analysis has been made for the performance of Regional climate models.

Table 1: show Input data's, their sources and lengths of records 


\begin{tabular}{|c|c|c|c|}
\hline \multirow{6}{*}{$\begin{array}{l}\text { Data Types } \\
\text { Meteorological data }\end{array}$} & Stations & Length of Records & Source of data \\
\hline & & $1980-2006$ & Ethiopian National Meteorological Agency \\
\hline & Addis Ababa & & \\
\hline & Boneya & & \\
\hline & Akaki & & \\
\hline & Sebeta & & \\
\hline
\end{tabular}

\section{RCM data}

The simulated Regional Climate models (RCM) which are found from Coordinated Regional Climate Downscaling experiment (CORDEX-Africa) driven by two GCM (CCCM-CanSEM2 and ICHE-EC-EARTH) under the African domain were used for the statistical analysis. These RCM models are good in simulating the climate variables from distance by being the representative of the entire catchment with spatial resolutions of $50 \mathrm{~km}\left(0.44^{\circ}\right)$. The lists of these RCM used in this study were summarized and depicted in the following (Table 2) with their simulation periods.

Table 2: Lists of used RCM with their founding institutions

\begin{tabular}{clcc}
\hline No & Models Found institute & RCM & $\begin{array}{c}\text { Simulation } \\
\text { Period }\end{array}$ \\
\hline 1 & & Swedish Meteorological and Hydrological Institute, Rossby & RCA4 \\
& Centre, Sweden & CCLM4-8- & $1980-2005$ \\
2 & & 17 & $1980-2006$ \\
& Climate Limited Area modelling Community (CLMcom), USA & RACMO22T & $1980-2005$ \\
\hline 3 & Koninklijk Nederland's Meteorologists Institute(KNMI), & & $1980-2008$ \\
\hline
\end{tabular}

\section{Methods}

RCM simulated data were extracted through ARCGIS 10.4.1 using their specified points or gridded points found in the surrounding catchment with their observational locations. The quality of simulated data extracted from those regional climate models was evaluated irrespective of measured or recorded data from four weather stations and the simulated values are interpolated by the IDW method to the observed data located at each station in the catchment. The study conducted so far by (Syst et al., 2010) indicates that the spatial interpolation of daily precipitation with the grid location of weather stations has been shown the comparison of geo-statistical and deterministic approaches. This study concludes that the performances of regional climate models in simulating climate variables were varied slightly referring to the density of gauging stations and further varying for a limited number of stations. In this study since the number of gridded points in the catchment are few, the Inverse Distance Weighting method was used 
to interpolate the simulated precipitation. When a small number of stations to be used for the interpolation of climate variables, IDW is better than the kriging method by realizing that the smallest value of RMSE shows better performance of the models (Dibaba, Miegel, and Demissie, 2019). The inverse Distance Weighting (IDW) method is mathematically defined as;

$$
V_{f}=\frac{\sum_{i=1}^{n} \frac{1}{d i^{2}} * V_{i}}{\sum_{i=1}^{n} d i^{2}}
$$

Where $V_{f}$ is the interpolated value at the considered station, $V_{i}$ is the data at grid point $i, d_{i}$ is the distance from grid point $i$ to the station, $n$ is the total number of grid points surrounding the stations.

$$
d=2 r \sin ^{-1}\left(\sqrt{\operatorname{Sin}^{2}\left(\frac{\varphi_{2}-\varphi_{1}}{2}\right)+\cos \varphi_{1} \cos \varphi_{2} \operatorname{Sin}^{2}\left(\frac{\emptyset_{2-} \emptyset_{1}}{2}\right)}\right)
$$

Where $d$ is the distance between two points on the earth's surface, $r$ is the earth's radius.

The performances of these Regional climate models were evaluated using complementary statistical parameters such as BIAS, RMSE, and Correlation Coefficient as shown below with their empirical formulas shown below on equations (1), (2), and (3). The smallest the values of Root Mean Square Error (RMSE) close to zero, the good the performance of RCM. Also, the BIAS measure the systematic error between the observed and simulated climate variable and zero indicate good performance, while values away from zero show the deviations to observed data. On the other hand, the correlation coefficient ( $r$ ) strongly values the linear relationship between average observed precipitation and average simulated by RCM. The value of ( $r$ ) close to one hint the models highly agree with the observed, and away from one implies less agreement between variables. The evaluation of the performances of RCM was conducted based on daily average precipitation which is simulated by each Regional climate model and spatially varied from observational data recorded within the catchment. Furthermore, the spatial maps of each RCM were developed for the observed map that developed from each station throughout the catchments which is the representation of distributed precipitation by that single station (Figure 9). Furthermore, the study also incorporates how RCMs were reproduce seasonal Precipitation and temperature distribution related to the inter-annual variability of these climate variables over the Akaki catchment.

$$
\begin{aligned}
& \text { BIAS }=\frac{1}{n} \sum_{i=1}^{n}(S i-O i) \ldots \ldots \ldots . . . \\
& \mathrm{RMSE}=\sqrt{\frac{1}{n} \sum_{i=1}^{n}(S i-O i)^{2}} \ldots . \\
& \mathrm{r}=\frac{\sum_{i=1}^{n}(S i-S m)(O i-O m)}{\sqrt{\sum_{i=1}^{n}(S i-S m)^{2}} \sqrt{\sum_{i=1}^{n}(O i-O m)^{2}}}
\end{aligned}
$$


Where $S$ is the simulated value of the RCMs and $O$ is the observed value of the climate variable, $i$ refer to the simulated and observed pairs, $\mathrm{n}$ is the total number of the pairs and $\mathrm{m}$ refers mean.

\section{Result And Discussions}

\subsection{Evaluation of Annual Cycle of Precipitation from Regional climate models}

The increment of warm climate has been accelerate the dynamic variability of the hydrological cycle, with changes in water balance components that altering rainfall patterns and magnitude and timings of runoff. Water stress has been profoundly affected by climate variables that govern the climate change to be caused. Indeed, different climate models developed by different institutions worldwide were estimated, simulated, and predict climate variables with their capability levels. These regional climate models simulate precipitation, maximum and minimum temperatures which are the most influential climate variables that affect climate change to be happen also expected to reproduce certain deviations among them. Based on these fundamental climate variables, their impact on streamflow was vitally important to be predicted and estimated for the future climate change projection. The simulation and estimation of precipitation in the basin were made using four selected regional climate models. The seasonal statistical analysis made on each catchment throughout the river basin indicates that CLLM4-8-17 and RACMO22T underestimate the annual precipitation during FMAM season at Addis Ababa and sebeta catchment with BIAS of $-28.6 \%$ and $-17.5 \%$ respectively as shown in (Figure 2 ). But the all models underestimate the simulated precipitation during JJAS at all stations except RACMO22T which was closely estimated very well at all stations during this season. indeed the estimation made by RCA4 and RACMO22T during the crucial rainfall season of the region (i.e., JJAS) was better than other Regional climate models.

Furthermore, the large proportion of annual rainfall was reproduced and coved high area almost estimated to $78 \%$ during JJAS season in all climate models throughout the river basin. Besides this, the highest mean annual rainfall was recorded during the JJAS season by RACMO22T with $1701 \mathrm{~mm}$. But the minimum rainfall was recorded in the FMAM season by the HIRHAM 5 model with $337 \mathrm{~mm}$. On the other hand, the mean annual observed rainfall was overestimated by CCLM4-8-17 and RACMO22T with BIAS of $28.6 \%$ and $17.5 \%$ respectively during FMAM season and underestimated by RCA4 and HIRMA5 with BIAS of $49.9 \%$ and $22 \%$ respectively. The correlation coefficient of RCM models with observed rainfall was good in the JJAS season as the coefficient of determination also strengthen and realize this conclusion. Indeed there are no single criteria that show the perfect performed RCMs, in many cases other than the combination of RMSE, BIAS, and Coefficient of variation. On the seasonally based analysis of climate models performance by statistical parameters, RCA4 and RACMO22T were best performed relative to other RCMs as it is seen from (Table 3 ) below. 
Table 3

Performance of the models in reproducing annual precipitation based on statistical parameters

\begin{tabular}{|c|c|c|c|c|c|c|}
\hline RCM & Seasons & $\begin{array}{l}\text { Mean Annual rainfall } \\
(\mathrm{mm})\end{array}$ & $\begin{array}{l}\text { Bias } \\
(\%)\end{array}$ & $\begin{array}{l}\mathrm{CV} \\
(\%)\end{array}$ & $\begin{array}{l}\text { RMSE } \\
\text { (mm/year) }\end{array}$ & $\begin{array}{l}\text { R-factor } \\
(\%)\end{array}$ \\
\hline \multirow[t]{2}{*}{ Observed } & JJAS & 1777 & - & 45.1 & - & - \\
\hline & FMAM & 505 & - & 11.8 & - & - \\
\hline \multirow{2}{*}{$\begin{array}{l}\text { CCLM4-8- } \\
17\end{array}$} & JJAS & 1653 & 7.5 & 59.8 & 60.8 & 0.45 \\
\hline & FMAM & 707 & -28.6 & 24.3 & 71.4 & 0.21 \\
\hline \multirow[t]{2}{*}{ RACMO22T } & JJAS & 1701 & 4.5 & 44.3 & 26.9 & 0.72 \\
\hline & FMAM & 697 & -17.5 & 34.0 & 67.9 & 0.51 \\
\hline \multirow[t]{2}{*}{ HIRHAM5 } & JJAS & 1148 & 54.8 & 34.6 & 222.4 & 0.36 \\
\hline & FMAM & 337 & 49.9 & 13.4 & 59.4 & 0.52 \\
\hline \multirow[t]{2}{*}{ RCA4 } & JJAS & 1351 & 31.5 & 23.4 & 150.6 & 0.46 \\
\hline & FMAM & 414 & 22 & 8.9 & 32.2 & 0.67 \\
\hline
\end{tabular}

\subsection{Evaluation of the Performance of RCM from Mean Climatology}

Evaluating climate models in different various ways is very important to adjust their performance for the use of climate change impact assessment. This performance of climate models is most of the time evaluated by using distinguished statistical parameters which are capable of estimating the difference between observed data and simulated. The characteristic of rainfall is depending on topography which varies with the complexity of the landscape of the region. Akaki catchment as a part of the Awash River basin has two rainfall seasons known locally by Kiremt (June-September) and Belg (March-May). High rainfall in this catchment was expected during Kiremt mostly by July and August. But from March through May to June moderate rainfall was mandatory which is very critical in the region for the initiation of socioeconomic and agriculture activities. The results from statistical analysis by this study indicate that CCLM4-8-17 underestimates the rainfall estimation with the highest Bias of $0.39 \mathrm{~mm}-1.47 \mathrm{~mm}$ and RMSE of $(-7.8 \mathrm{~mm} /$ day). Also, HIRHAM5 underestimate the rainfall with medium Bias ranged from $0.17 \mathrm{~mm}-0.46 \mathrm{~mm}$ and RMSE of $(-6.7 \mathrm{~mm} /$ day). Relatively RACMO22T was better even though overestimate the rainfall at sebeta stations with RMSE $(-4.6 \mathrm{~mm})$ and BIAS of $-0.21 \mathrm{~mm}$. Moreover, CCLM48-17 and HIRHAM5 models were underestimating the rainfall at Addis Ababa, Boneya, and Sebeta stations. But RCA4 and RACMO22T models were relatively good at all stations except RCA4 underestimate at Addis Ababa with BIAS of $-0.46 \%$ and RACMO22T at sebeta station with BIAS of $-0.21 \%$ and RMSE of $-4.6 \mathrm{~mm} /$ day as illustrated in (Table 4) below. 
The seasonal analysis over the Akaki rivers basin indicates that climate models were more capable of the simulated wet season than the dry season. in general RCA4 and RACMO22, T was best in the simulation of daily rainfall relative to other Regional climate models compared in this study which was the same conclusion drawn by (Dibaba, Miegel, and Demissie, 2019), (Reder et al., 2020) on RACMO22T. on the other way, while using the correlation coefficient for assessment of the performance of RCMs, simulated precipitation of two models (CCLM4-8-17 and HIRHMA5) were poorly correlated at all stations with observed precipitation. This simply indicates that simulated precipitation was unable to fit with the observed stations. Although these two RCM was weakly performed in the simulation of monthly precipitation, the correlation values indicate that it's positively correlated with the observed. On the other hand, RACMO22T and RCA4 were better correlated at all stations with more than $50 \%$ correlation coefficient values at Addis Ababa and Boneya stations. Furthermore, all RCM were poorly correlated the downstream of Akaki River's basin in simulating annual precipitations as is shown in (Figure 3) below.

Table 4

Show the relation of observed and simulated Rainfall on daily basis by Statistical parameters

\begin{tabular}{|c|c|c|c|c|c|}
\hline Stations & Performance Statistics & CCLM4-8-17 & RACMO22T & HIRHAM5 & RCA4 \\
\hline \multirow[t]{3}{*}{ Addis Ababa } & RMSE & -7.8 & 3.8 & -6.7 & 6.8 \\
\hline & BIAS & 0.6 & 0.5 & 0.46 & -0.46 \\
\hline & $r$ & 0.33 & 0.7 & 0.5 & 0.89 \\
\hline \multirow[t]{3}{*}{ Boneya } & RMSE & 6.9 & 1.23 & -2.8 & 1.7 \\
\hline & BIAS & 1.47 & 0.49 & -0.46 & 0.50 \\
\hline & $r$ & 0.4 & 0.5 & 0.4 & 0.4 \\
\hline \multirow[t]{3}{*}{ Akaki } & RMSE & -2.7 & 5.4 & 3.4 & 1.8 \\
\hline & BIAS & -1.4 & 0.3 & -0.4 & 0.5 \\
\hline & $r$ & 0.3 & 0.6 & 0.2 & 0.6 \\
\hline \multirow[t]{3}{*}{ Sebeta } & RMSE & 6.3 & -4.6 & 4.2 & 4.4 \\
\hline & BIAS & -0.39 & -0.21 & -0.17 & 0.19 \\
\hline & $r$ & 0.41 & 0.52 & 0.45 & 0.56 \\
\hline
\end{tabular}

\subsection{Evaluation of Mean Annual cycle of Temperature from Regional Climate Models}

Temperature is a key climate variable that is used as raw input for hydrological models in predicting the situation related to hydrological processes. Currently, both maximum and minimum temperatures show an increasing trend at all catchments and signify global warming. Using these Climate models which simulate the maximum and minimum temperatures is very essential to predict the future climate change 
impacts on the hydrological process as they are not show a constant mode of change due to climate models sometimes underestimate and overestimate the variables. As seen from the following (Figure 5) CCLM4-8-17 and HIRHAM5 were underestimated both maximum and minimum temperature during the spring season (FMAM) and overestimate the minimum temperature during the summer season (JJAS). However, both maximum and minimum temperature trends show an increasing rate per year.

During the winter season, all models underestimate maximum temperature except RCA4 which shows an overestimation to the same extent. but almost all models overestimate minimum temperature in the same season relatively by a half percent. But RACMO22T and RCA4 models show better performance than others in simulating both maximum and minimum temperatures across the seasons as they performed the same by precipitations during seasonal analysis. However, maximum Temperature at Akaki and Sebeta stations was underestimated by all Models in all seasons except overestimated by the RCA4 model at Sebeta Station during spring (FMAM) season as seen from (Figure $4 \& 5$ ) below. On the other hand, CCLM4-8-17 and HIRHMA5 models were highly biased which shows negative biases, and RACMO22T and RCA4 models are also moderately biased but indicate positive bias. This is to means that if the value of BIAS statistical parameters shows a negative value it's to means that the minimum temperature simulated by RCM is less than the gauged value. This scenario completely shows the underestimation of temperature by Regional climate models. On another side, BIAS shows a positive value which indicates RCM is shown an overestimation. Hence, RACMO22T and RCA4 models show minimum temperature overestimation to some level of extraordinary extents.

In the case of maximum temperature, CCLM4-8-17 show full underestimation, while, others show underestimation and overestimation characteristics. But HIRHMA5 shows a little bit good simulation of maximum temperature than ever seen in this study. However, RCA4 and RACMO22T were still show some modified and coherent behavior in the simulation of maximum temperature related to the observed. Even though the value of RMSE is greater than one, still RCA4 and RACMO22T show good closeness in simulating maximum temperature as shown in (Figure 4) below. Generally, minimum Temperature simulated by RACMO22T and RCA4 with BIAS of $1.5^{\circ} \mathrm{C}$ and $1.8^{\circ} \mathrm{Crespectively} \mathrm{shows} \mathrm{the} \mathrm{moderate}$ deviation between the observed and simulated minimum temperature. On the other hand, when RMSE was considered, except RCA4 and RACMO22T, the other climate models (CCLM4-8-17 and HIRHMA5) were highly deviated with RMSE value greater than four which was far from one at all stations that concluded too by (Worku et al., 2018). But maximum temperature simulated with CCLM4-8-17 shows bad underestimation with BIAS of $-4^{\circ} \mathrm{C}$ at all stations. however, the other climate models show fair BIAS that is not considered as extreme biases in compare to the other models.

\subsection{Inter-Annual Variability of Precipitations and Temperature Anomalies}

The analysis of temporal patterns related to both precipitations and temperature distribution in the catchment is very important to predict future climatological variability such as flooding or drought with 
its consequences. In this study, all inter-annual variability analysis was based on the main rainfall season known in the country and which is from June to September (JJAS) and from February to May (FMAM) with moderate rainfall. The computation of standard anomalies related to both precipitations and temperature was derived from the complete 17years period of 1990-2006. The seasonal variations of both precipitations and temperature data were studied by using standard deviation to identify the depth of variation between the simulated climate variables and gauged parameters. This inter-annual variability of seasonal precipitation anomalies over Akaki catchment was represented in (Figure 6) for mean observed and simulated by four regional climate models. The RCM used in this study was simulated the precipitation and temperatures anomalies quite different during wet seasons particularly (JJAS and MAM) and dry season (ONDJ). Indeed, the wet season in this region was during spring (Belg) and summer (Kiremt), and the dry season was known as (Bega). Almost all RCMs gave good information and high skills in predicting and simulating the inter-annual variability of the wet season than dry seasons. This indicates that climate models have good performances and capability in simulating mean precipitation during the main rain season than temperate (dry) seasons. On the other hand, RCMs showed good simulation for both maximum and minimum temperature during the temperate (dry) season than wet seasons. This shows the satellite extraction tendency and performance of RCM's in capturing precipitation and temperature was mostly rely on the seasons where the climate variables are expected to be reproduced which also concluded by (Meier et al., 2016). In this case, both RACMO22T and RCA4 have shown better performance in capturing the inter-annual variability of precipitation in all-season than others. But in the main rainfall season specifically, during summer (JJAS), all models except RACMO22T was shown poor performances. However, most RCM has good performance in reproducing mean precipitations during crucial rainfall seasons with some exceptions.

Coming to Correlation coefficients, all RCMs relatively show good correlation for all parameters considered in this evaluation. Comparatively RACMO22T and RCA4 were correlated better than the others with 0.52 and 0.43 respectively in simulations of interannual variability for precipitations during the summer season. But in spring season Regional climate models, i.e. RACMO22T and RCA4 were performed less when compared to the others with correlation coefficients of 0.53 and 0.30 respectively which was conclude by (Endris, P Omondi, et al., 2013) too. Indeed, the short time season of precipitation experienced a large degree of inter-annual variability than the long precipitation seasons (Kjellström et al., 2016). On the other hand, CCLM4-8-17 and RCA4 were performed very well during FMAM season for simulation of interannual Variability of maximum temperature with correlation coefficients of 0.83 and 0.87 respectively. But RACMO22T and HIRHAM5 were better performed in the summer season. While inter-annual variability of Minimum Temperature anomalies is less evident over the catchment as the correlation coefficient value indicates poor performance for all RCMs in the considered seasons. In general, interannual variability of maximum temperature was quite significant during the dry season than wet season which is opposite to the precipitations. 
Table 5

Correlation Coefficient derived from Precipitation, Maximum and Minimum Temperatures of four RCMs based on Seasonal Occurrences

\begin{tabular}{|c|c|c|c|c|c|}
\hline Climate Variables & Seasons & CCLM4-8-17 & RACM022T & HIRHAM5 & RCA4 \\
\hline \multirow[t]{3}{*}{ Precipitations } & Annual & 0.43 & 0.76 & 0.57 & 0.66 \\
\hline & JJAS & 0.29 & 0.52 & 0.18 & 0.43 \\
\hline & FMAM & 0.42 & 0.43 & 0.5 & 0.03 \\
\hline \multirow[t]{3}{*}{ Maximum Temperature } & Annual & 0.36 & 0.59 & 0.72 & 0.41 \\
\hline & JJAS & 0.25 & 0.4 & 0.53 & 0.29 \\
\hline & FMAM & 0.83 & 0.14 & 0.28 & 0.87 \\
\hline \multirow[t]{3}{*}{ Minimum Temperature } & Annual & 0.18 & 0.21 & 0.32 & 0.23 \\
\hline & JJAS & 0.18 & 0.046 & 0.052 & 0.12 \\
\hline & FMAM & 0.53 & 0.42 & 0.28 & 0.38 \\
\hline
\end{tabular}

A spatial map is the most imperative way to identify the deviation between the observed and simulated distribution of precipitation and temperatures through developing the spatiotemporal map based on annual or monthly average or daily average rainfall and maximum-minimum temperature of the watershed. The recent study conducted by (Endris, P Omondi, et al., 2013) on spatial interpolation of daily rainfall on regular patterns of catchments has shown the comparison of different geo-statistical and deterministic approaches. The study also indicated, the performance varied slightly according to the density of the gauging stations and vary strongly for a smaller number of stations. The developed spatial map from Average Precipitations from different RCMs indicated below show that most RCM performance in representing sampled locations from the neighbour station through interpolation was poor. Particularly the spatial distribution of daily precipitation over the catchment was closely represented by CCLM4-8-17 was highly intensive rainfall ranged from $4.6 \mathrm{~mm} /$ day $-5.8 \mathrm{~mm} /$ day which is similar to the observed with limited area coverage. However, the rainfall spatial distribution represented by the spatial map of the RACMO22T model over the catchment with maximum rainfall of $2 \mathrm{~mm} /$ day to $2.5 \mathrm{~mm} /$ day was also represented. Generally, all RCMs were spatially representing the daily precipitation at a different level of performance by their simulation capability which was also summarized by (Ly, Charles, and Degré, 2011). Therefore, the spatial map developed here below (Figure 9) indicates that the spatially interpolated value of distributed precipitation from the gauging stations of each RCM along the catchment was varied to the gauging locations.

\section{Conclusion}


In this study, it was attempted to dig out the performance of RCM to simulate mean Annual Climatology, inter-annual variability, and Annual cycle of Precipitation and temperature over Akaki catchment. In this evaluation of RCMs, much uncertainty related to each RCM and their capability of the simulation was identified and estimated using Statistical parameters such as standard deviation, RMSE, BIAS, and Correlation coefficient. The performance of these climate models in attaining certain aspects of gauging precipitations indicates that the simulated and observed climate variables were not shown complete variation. But there should be a certain difference among RCM in simulating the precipitation against observed. Moreover, despite their performance, it was recognized that all RCM simulated values show reasonable bias that needs correction before use for hydrological modeling. The results from statistical analysis by this study indicate that CCLM4-8-17 underestimates the rainfall estimation with the highest Bias of $0.39 \mathrm{~mm}-1.47 \mathrm{~mm}$ and RMSE of $(-7.8 \mathrm{~mm} /$ day). Also, HIRHAM5 underestimates the rainfall with medium Bias ranged from $0.17 \mathrm{~mm}-0.46 \mathrm{~mm}$ and RMSE of $(-6.7 \mathrm{~mm} /$ day). Relatively RACMO22T was better even though overestimate the rainfall at sebeta stations with RMSE $(-4.6 \mathrm{~mm})$ and BIAS of -0.21 mm. Moreover, CCLM4-8-17 and HIRHAM5 models were underestimating the rainfall at Addis Ababa, Boneya, and Sebeta stations. But RCA4 and RACMO22T models were relatively good at all stations except RCA4 with mean climatology. All RCMs relatively show a good correlation for all parameters considered in this evaluation. Comparatively RACMO22T and RCA4 were correlated better than the others with 0.52 and 0.43 respectively in simulations of interannual variability for precipitations during the summer season. But in spring season Regional climate models, i.e. RACMO22T and RCA4 were performed less when compared to the others with correlation coefficients of 0.53 and 0.30 respectively. Moreover, the short time season of precipitation experienced a large degree of inter-annual variability than the long precipitation seasons. Generally, seasonal analysis over the Akaki River basin indicates that climate models were more capable of the simulated wet season than dry seasons and RACMO22T and RCA4 were performed better than the others in all aspects for precipitation meanwhile, RACMO22T perform less for simulation of temperature against the mean observed.

\section{Declarations}

\section{Acknowledgement}

I would like to express my deep gratitude to Ethiopian meteorological Agency, water, irrigation and Electricity institute for their great willingness through giving me any necessary data for the accomplishments of this research. Also I would like to say many thanks to those who gave advice and support for this top achievement.

\section{Data Availability Statement}

All necessary data were incorporated and included in the paper. If more supplementary data is requested; it will be provided to the concern body.

\section{Declaration of competing interest}


The Author declares no conflicts of interest at all.

\section{Funding Statements}

The research did not receive any specific fund rather perform as part of an employment at Jimma University, institute of Technology, Ethiopia.

\section{References}

Asore (2012) 'Impact of climate change on potential evapotranspiration and runoff in the Awash River basin in Ethiopia', (January).

Climate Change 2014 Synthesis Report IPCC (2014) 'Climate Change 2014 Synthesis Report Summary Chapter for Policymakers', Ipcc, p. 31. doi: 10.1017/CB09781107415324.

Crop, A. et al. (2012) 'Regional climate model performance and prediction of seasonal rainfall and surface temperature of uganda', 20, pp. 213-225.

Dibaba, W. T., Miegel, K. and Demissie, T. A. (2019) 'Evaluation of the CORDEX regional climate models performance in simulating climate conditions of two catchments in Upper Blue Nile Basin', Dynamics of Atmospheres and Oceans. Elsevier, 87(May), p. 101104. doi: 10.1016/j.dynatmoce.2019.101104.

Endris, H. S., Omondi, Philip, et al. (2013) 'Assessment of the performance of CORDEX regional climate models in simulating East African rainfall', Journal of Climate, 26(21), pp. 8453-8475. doi: 10.1175/JCLID-12-00708.1.

Endris, H. S., Omondi, P, et al. (2013) 'Assessment of the Performance of CORDEX Regional Climate Models in Simulating East African Rainfall Assessment of the Performance of CORDEX Regional Climate Models in Simulating East African Rainfall', (November). doi: 10.1175/JCLI-D-12-00708.1.

Fang, G. et al. (2015) 'Climate Change Impact on the Hydrology of a Typical Watershed in the Tianshan Mountains', Advances in Meteorology, 2015. doi: 10.1155/2015/960471.

Gashaw, M. and Didita, M. (2015) 'Ethiopian Panel on Climate Change: First Assessment Reoport, Working Group II Biodiversisty and Ecosystems', Ethiopian Academy of Sciences, (January 2015), p. 210 p.

Gunathilake, M. B. et al. (2020) 'Evaluation of Future Climate and Potential Impact on Streamflow in the Upper Nan River Basin of Northern Thailand', Advances in Meteorology, 2020. doi:

$10.1155 / 2020 / 8881118$.

IPCC (2014) Climate Change 2014: Mitigation of Climate Change. Summary for Policymakers and Technical Summary, Climate Change 2014: Mitigation of Climate Change. Part of the Working Group III 
Contribution to the Fifth Assessment Report of the Intergovernmental Panel on Climate Change. doi: 10.1017/СВ09781107415416.005.

Kang, Y. et al. (2020) 'Quantitative analysis of hydrological responses to climate variability and land-use change in the hilly-gully region of the loess plateau, China', Water (Switzerland), 12(1). doi: 10.3390/w12010082.

Kjellström, E. et al. (2016) 'Production and use of regional climate model projections - A Swedish perspective on building climate services', Climate Services, 2-3, pp. 15-29. doi: 10.1016/j.cliser.2016.06.004.

Ly, S., Charles, C. and Degré, A. (2011) 'Geostatistical interpolation of daily rainfall at catchment scale: The use of several variogram models in the Ourthe and Ambleve catchments, Belgium', Hydrology and Earth System Sciences, 15(7), pp. 2259-2274. doi: 10.5194/hess-15-2259-2011.

Matiu, M. et al. (2020) 'Evaluating Snow in EURO-CORDEX Regional Climate Models with Observations for the European Alps: Biases and Their Relationship to Orography , Temperature, and Precipitation Mismatches'.

Meier, C. I. et al. (2016) 'Describing the interannual variability of precipitation with the derived distribution approach: effects of record length and resolution', pp. 4177-4190. doi: 10.5194/hess-20-4177-2016.

Mekonnen, D. G. et al. (2011) The impact of climate change on mean and extreme state of hydrological variables in Megech watershed, Upper Blue Nile, Extreme Hydrology and Climate Variability. Elsevier Inc. doi: 10.1016/B978-0-12-815998-9.00011-7.

Menna, B. Y. (2017) 'Simulation of Hydro Climatological Impacts Caused by Climate Change: The Case of Hare Watershed, Southern Rift Valley of Ethiopia', Hydrology: Current Research, 08(02). doi: 10.4172/2157-7587.1000276.

Reder, A. et al. (2020) 'Performance evaluation of regional climate model simulations at different spatial and temporal scales over the complex orography area of the Alpine region', Natural Hazards. Springer Netherlands, (0123456789). doi: 10.1007/s11069-020-03916-X.

Syst, E. et al. (2010) 'Spatial interpolation of daily rainfall at catchment scale: a case study of the Ourthe and Ambleve catchments, Belgium', Hydrology and Earth System Sciences Discussions, 7(5), pp. 73837416. doi: 10.5194/hessd-7-7383-2010.

Tan, Y. et al. (2020) 'Selection of effective GCM bias correction methods and evaluation of hydrological response under future climate scenarios', Climate, 8(10), pp. 1-21. doi: 10.3390/cli8100108.

Taye, M. T. (2018) 'Climate Change Impact on Water Resources in the Awash Basin, Ethiopia', pp. 1-16. doi: 10.3390/w10111560. 
Worku, G. et al. (2018) 'Evaluation of Regional Climate Models Performance in Simulating Rainfall Climatology of Jemma Sub-basin, Upper Blue Nile Basin, Ethiopia', Dynamics of Atmospheres and Oceans. Elsevier B.V. doi: 10.1016/j.dynatmoce.2018.06.002.

Yesuf, H. M. et al. (2016) 'Streamflow prediction uncertainty analysis and verification of SWAT model in a tropical watershed', Environmental Earth Sciences. Springer Berlin Heidelberg. doi: 10.1007/s12665-0165636-z.

Zhang, Y. et al. (2016) 'Hydrological processes in changing climate, land use, and cover change', Advances in Meteorology, 2016. doi: 10.1155/2016/7273424.

\section{Figures}

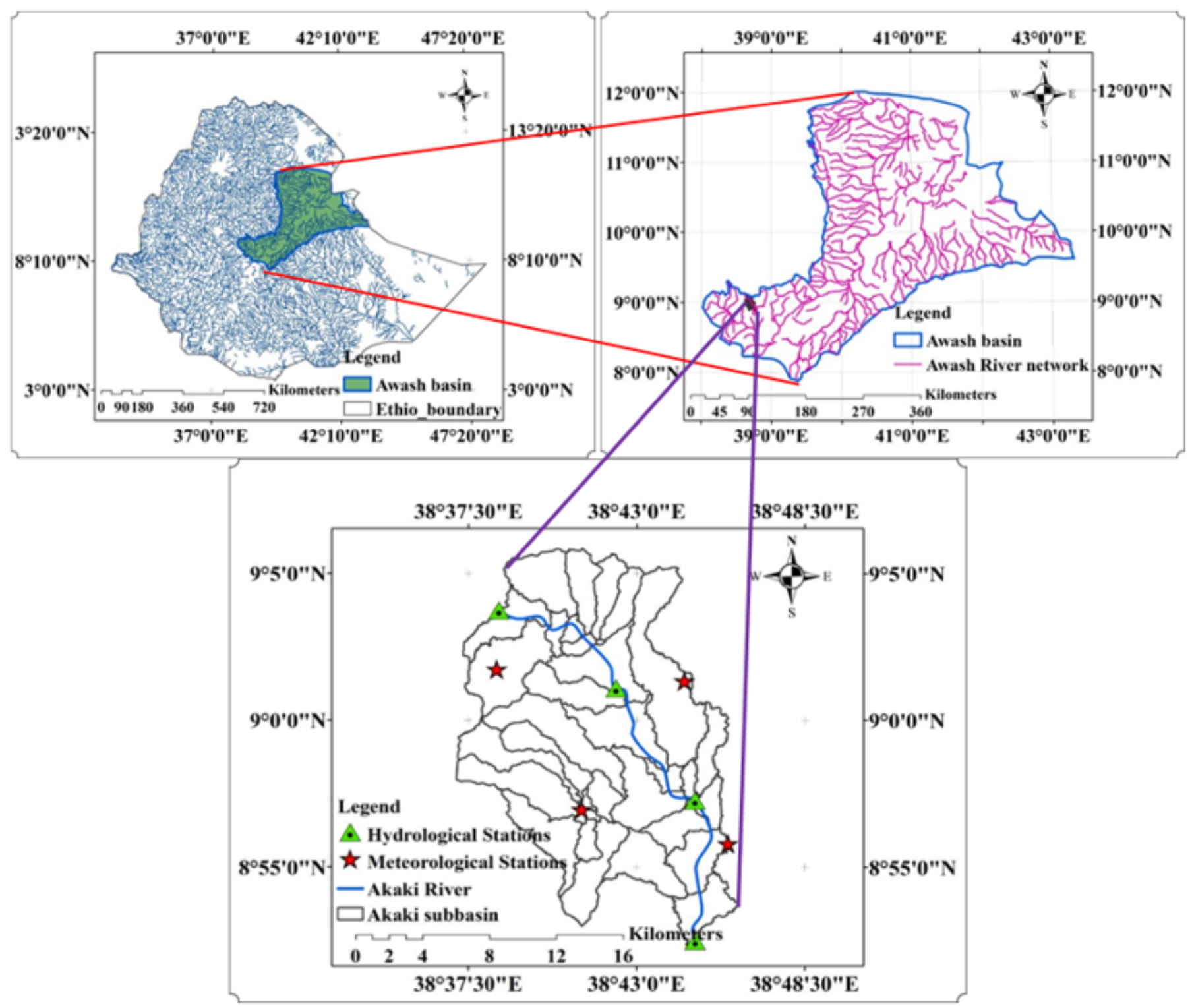

Figure 1 
Map of the study area

(a) observed precipitation against simulated by four Regional climate models (RCM) at Addis Ababa Catchment

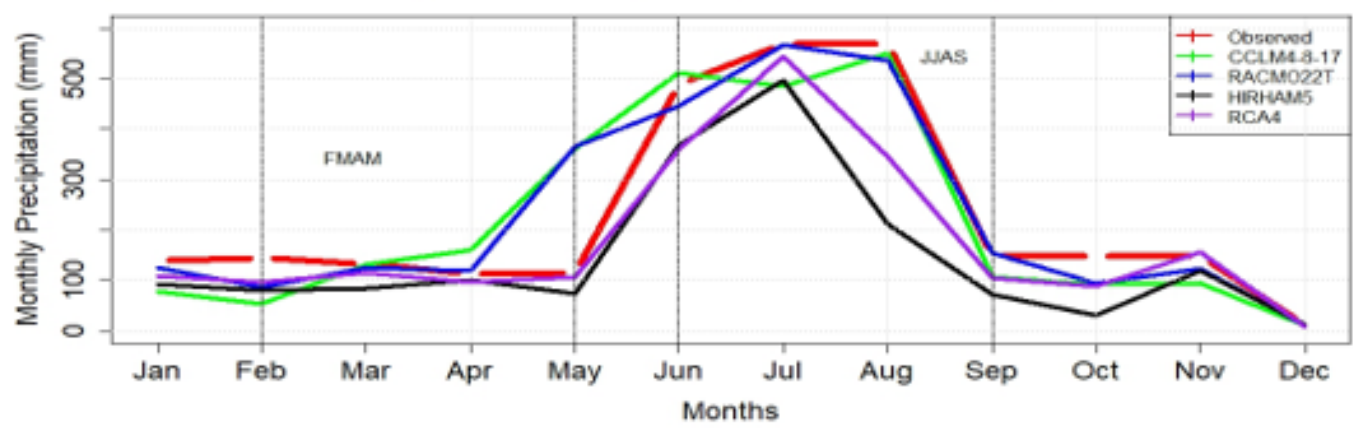

(b) observed precipitation against simulated by four Regional climate models (RCM) at Sebeta Catchment

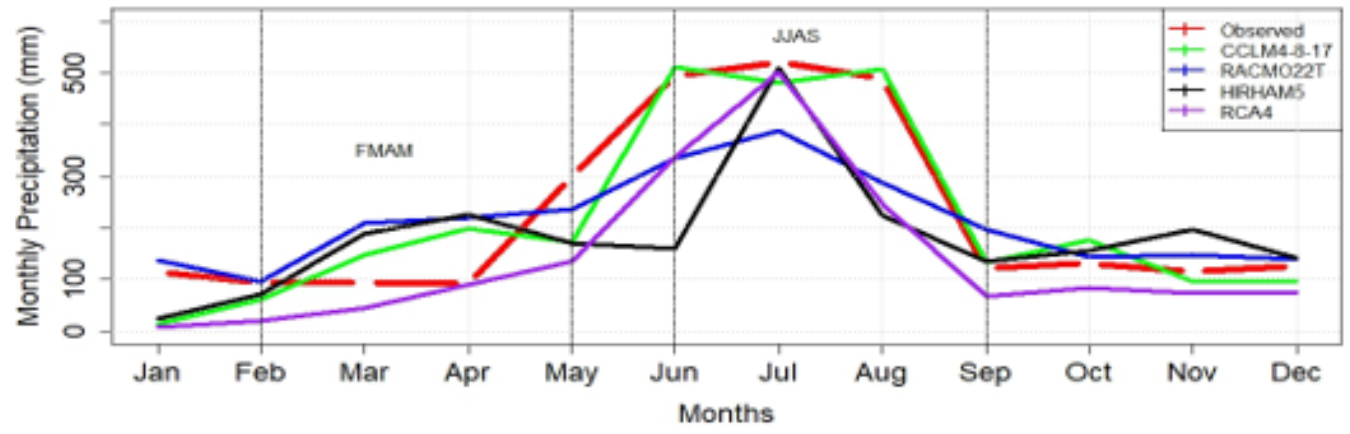

(c) observed precipitation against simulated by four Regional climate models (RCM) at Akaki Catchment

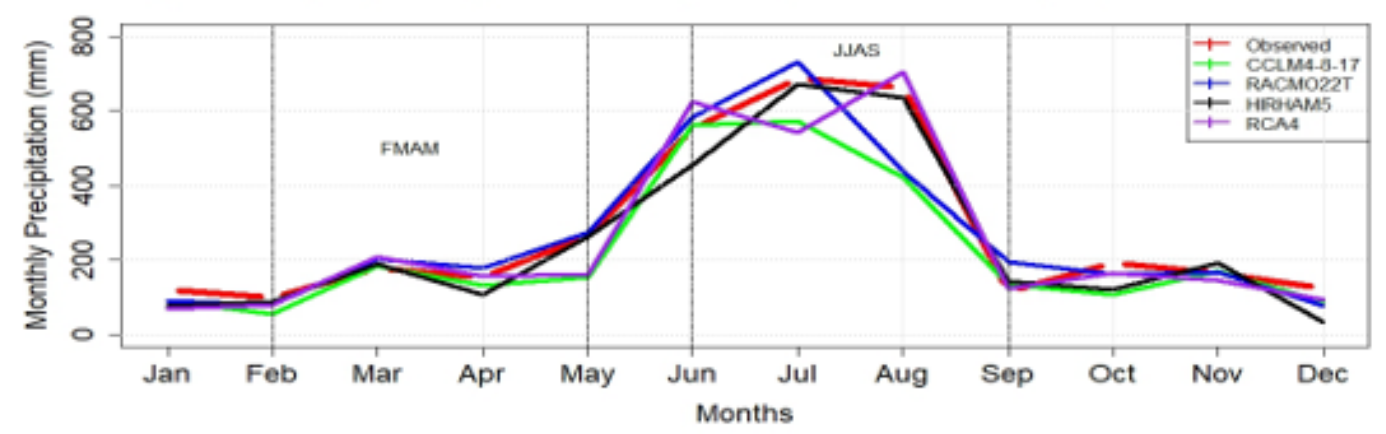

(d) observed Precipitation against simulated by four Regional climate models (RCM) at Boneya station

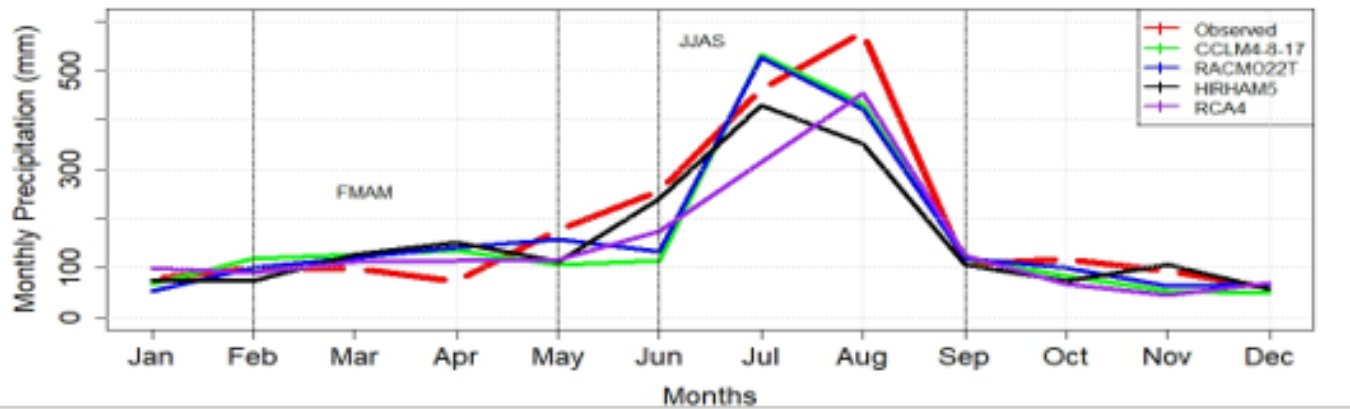

Figure 2

Mean Annual Cycle Analysis of Precipitation based on rain Season occurrences from 4RCMs 

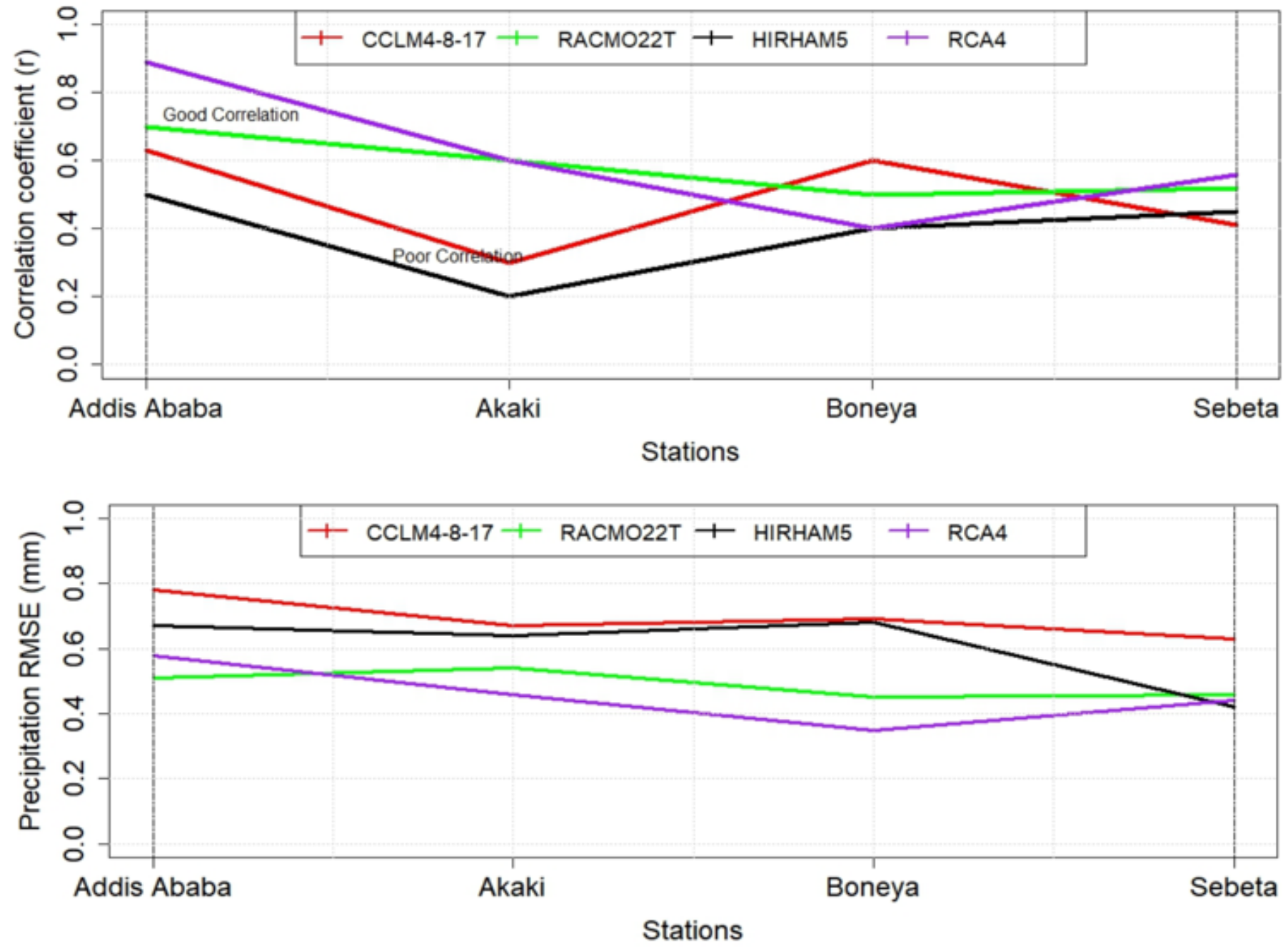

Figure 3

Correlation Coefficients' ( $r$ ) and RMSE of Mean Annual Precipitation between simulated and observed at Akaki Catcments 

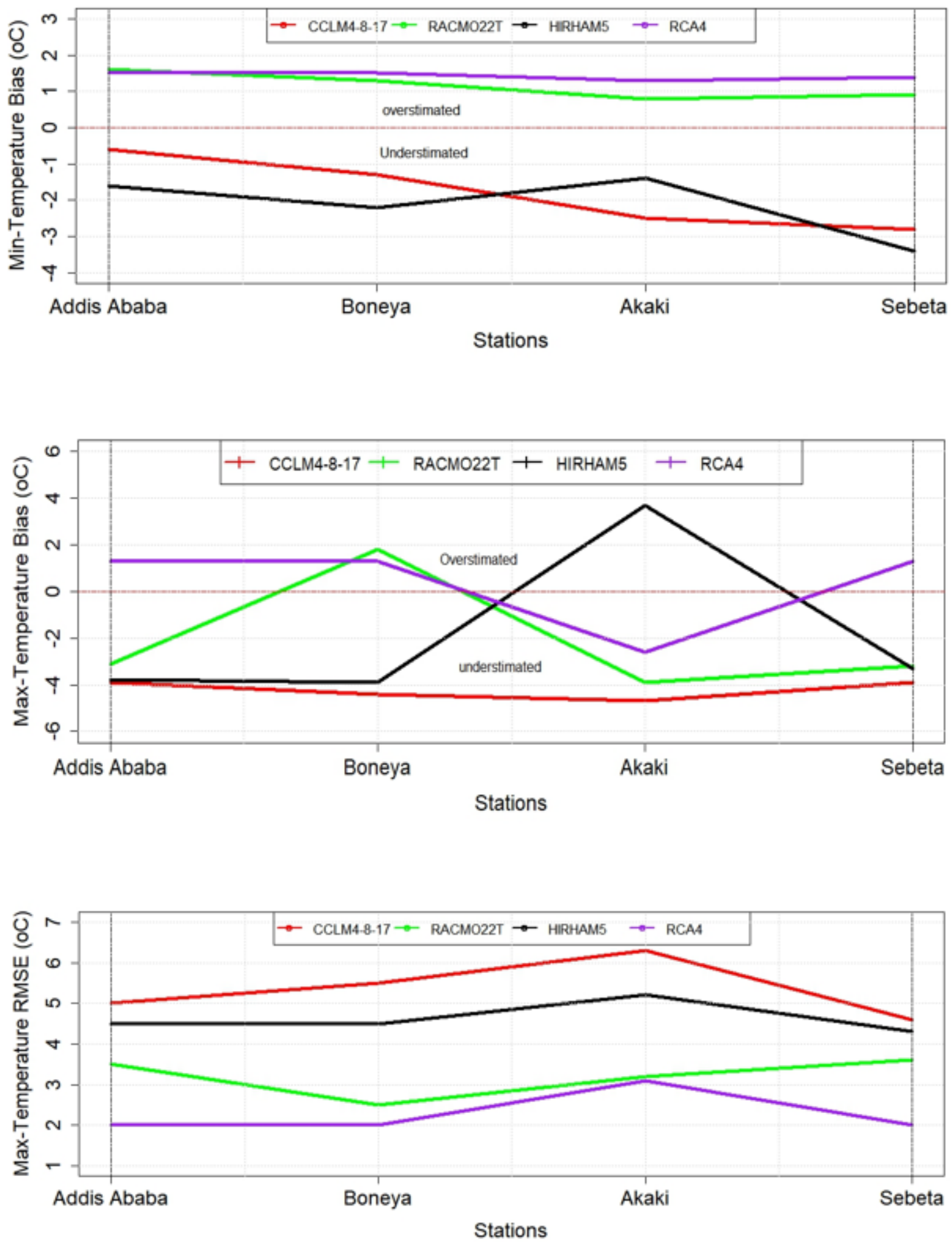

Figure 4

RMSE and BIAS of Mean Annual Minimum and Maximum Temperature between Simulated and Observed at Akaki catchments' 

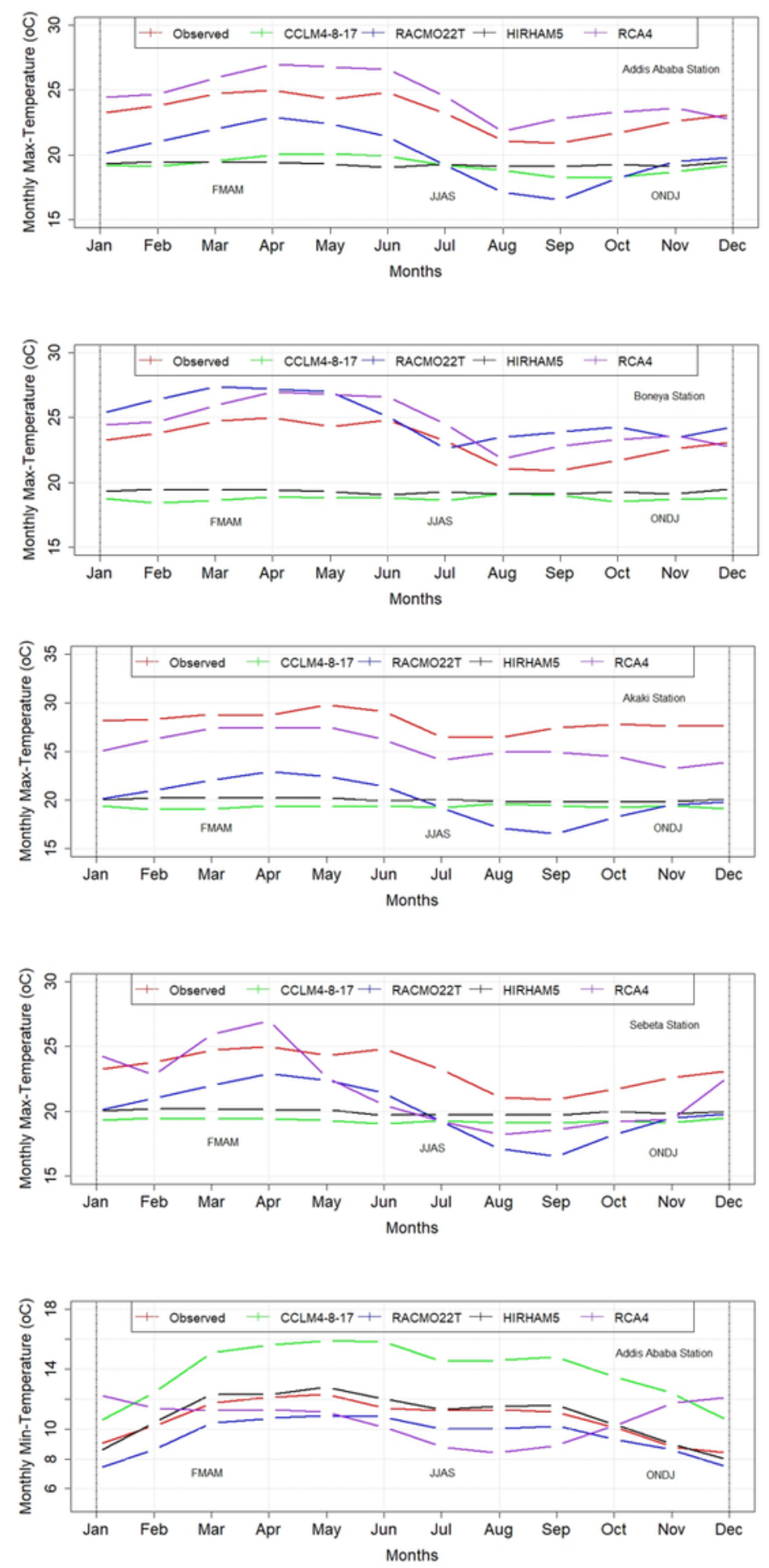

\section{Figure 5}

Evaluation of Mean Annual cycle of maximum and minimum Temperatures from 4RCMs 

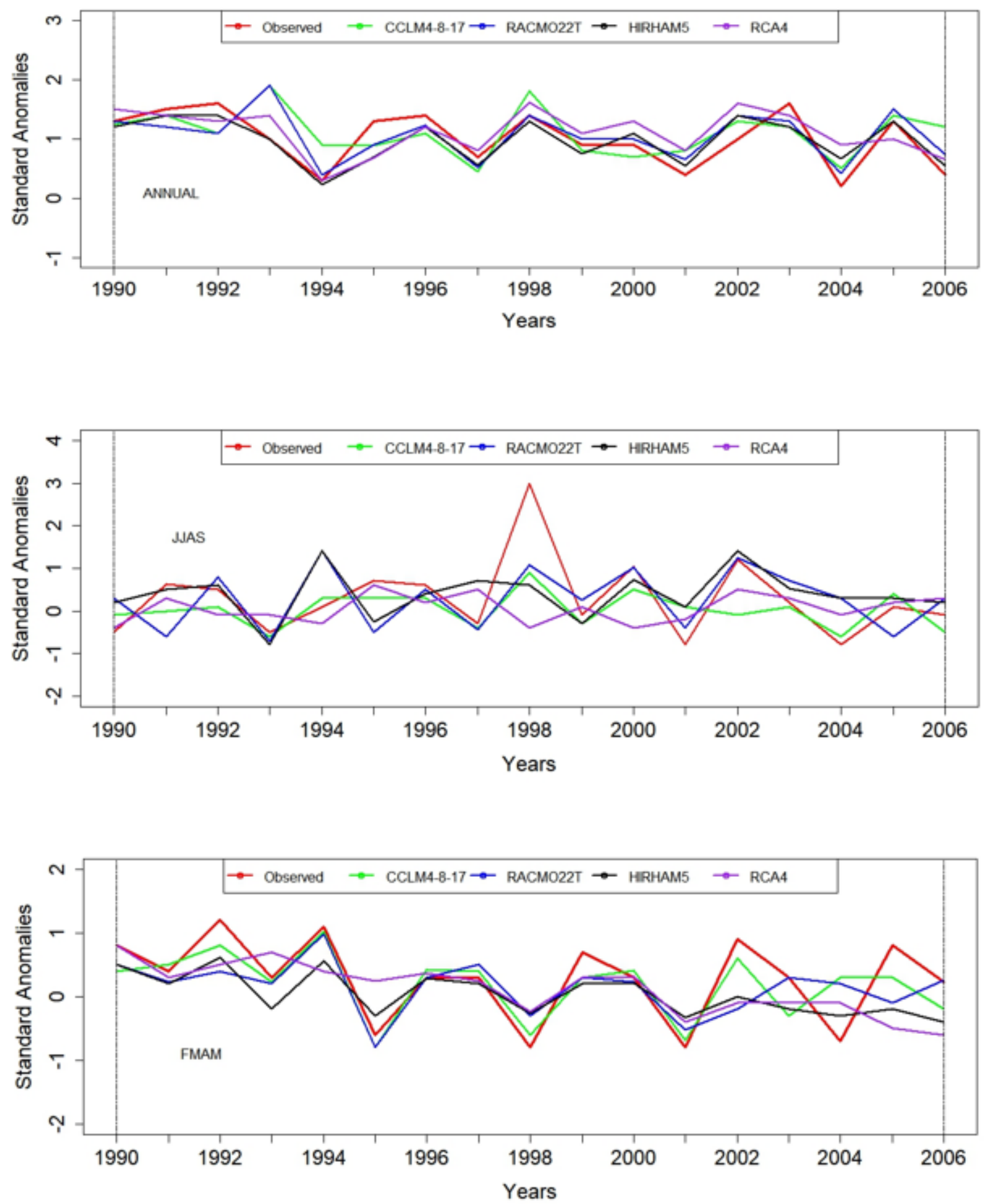

Figure 6

Inter Annual Variability of standardized Precipitation Anomalies during summer (JJAS) and spring (FMAM) seasons of moderate rainfall 

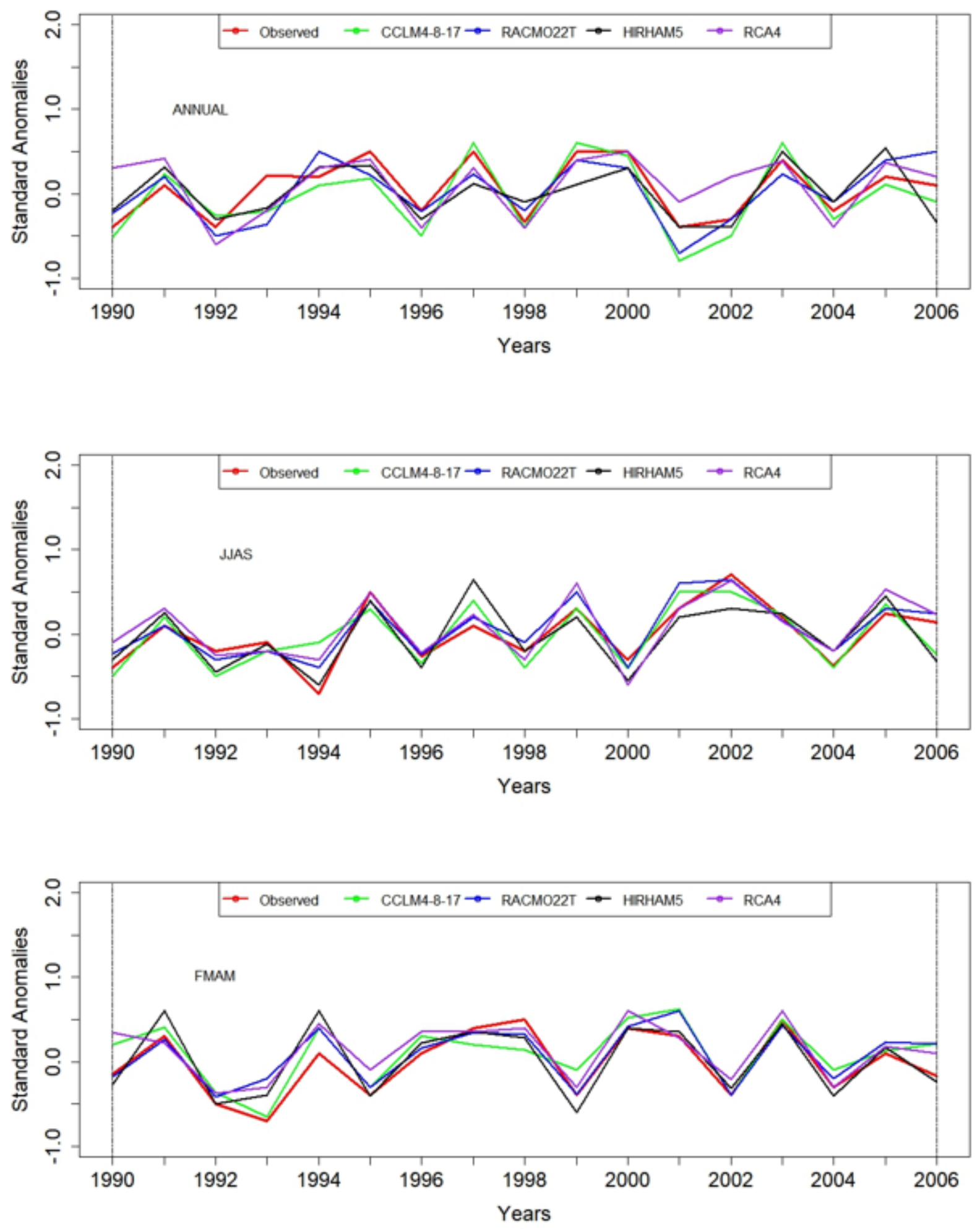

Figure 7

Inter Annual Variability of Standardized Maximum Temperature Anomalies over Akaki River basin 

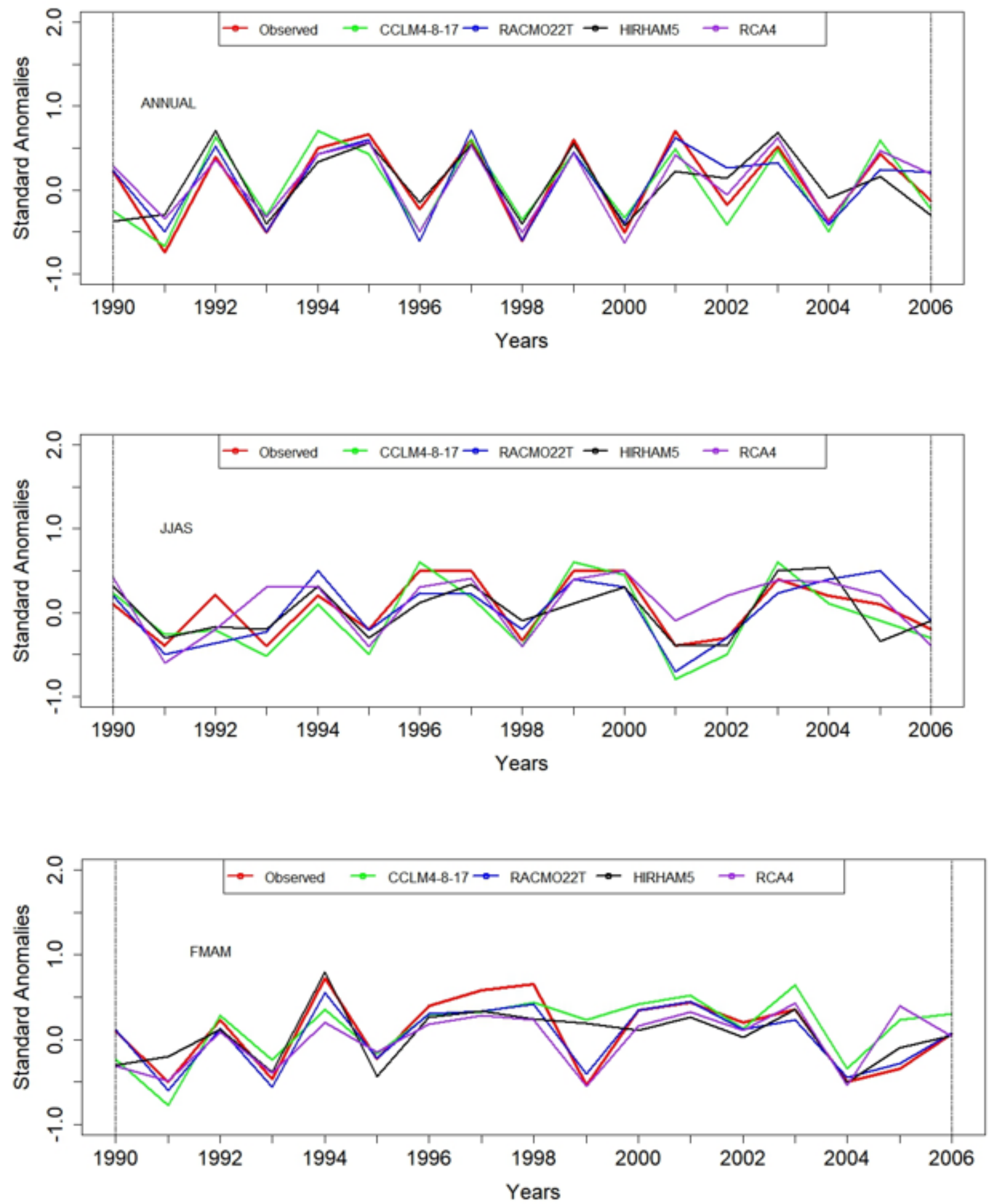

Figure 8

Inter Annual Variability of Standardized Minimum Temperature Anomalies over Akaki River basin 

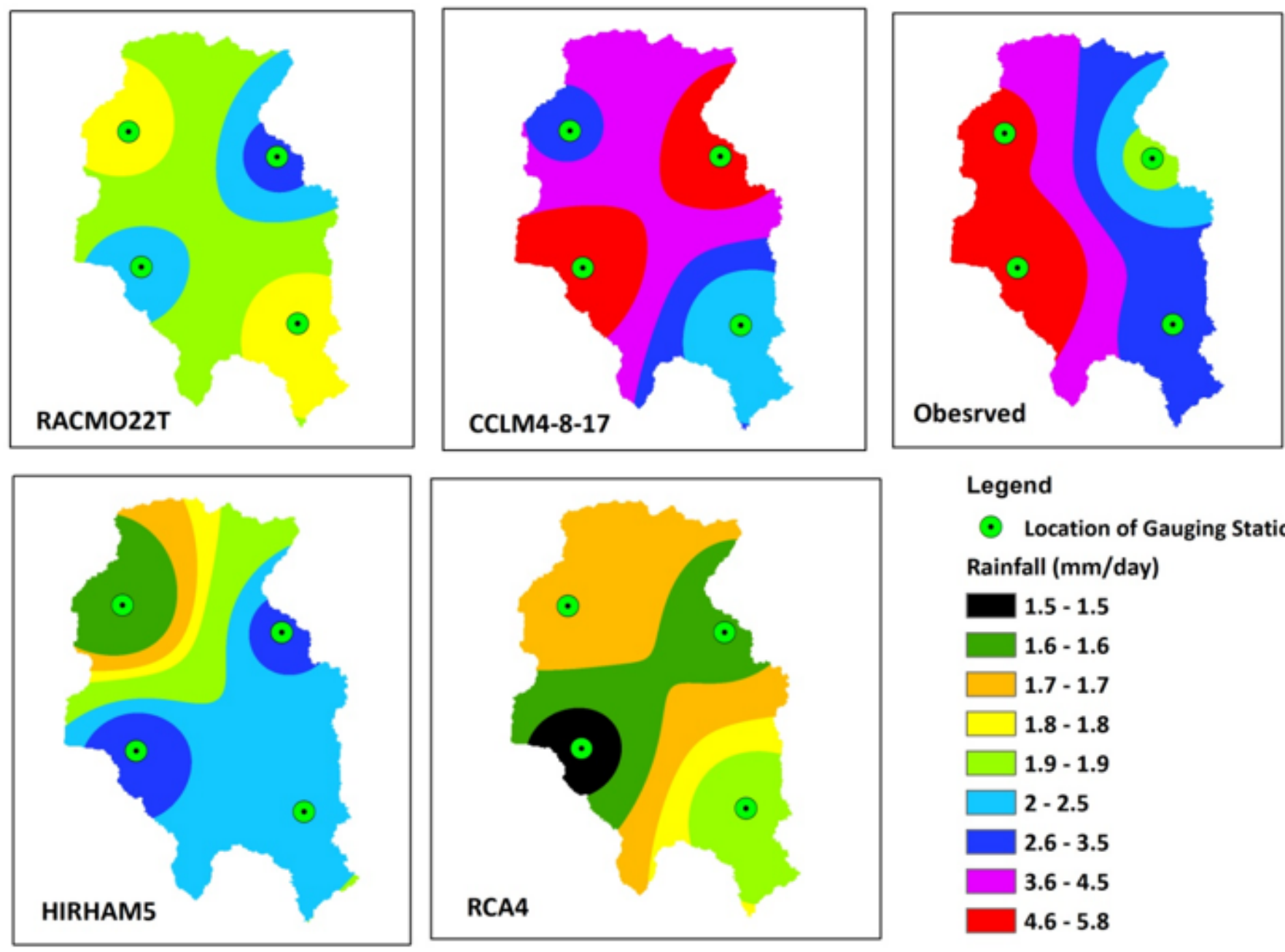

Legend

$\odot$ Location of Gauging Stations Rainfall (mm/day)

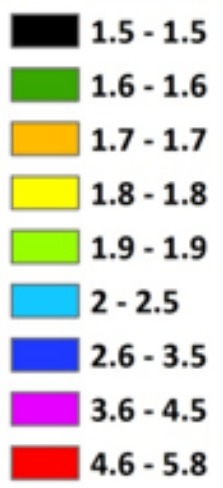

Figure 9

Spatial distribution of Precipitations by four Regional Climate Models at Akaki catchment 